\title{
O tratamento do "erro" nas produções textuais: a revisão e a reescritura como parte do processo de avaliação formativa
}

\author{
The treatment of the "wrong" in the textual \\ productions: revision and rewriting \\ as part of the formative evaluation process
}

Ana Dilma de Almeida PEREIRA

\begin{abstract}
RESUMO
O propósito deste artigo é apresentar algumas considerações em torno dos processos de escritura-revisão-reescritura no ensino-aprendizagem da língua materna. Considera a avaliação formativa como importante estratégia no processo da produção textual e da intervenção didática a partir de uma abordagem interacional.

Palavras-chave: abordagem interacional, avaliação formativa, escritura-revisão-reescritura, intervenção didática.

ABSTRACT

The purpose of this article is to present some considerations around the processes of writing-revision-rewriting in the language teachinglearning. It considers the formative evaluation as important strategy in the process of the textual production and the didactic intervention from an interactional approach.
\end{abstract}

Index Terms: didactic intervention, formative evaluation, interactional approach, writing-revision-rewriting. 


\section{Introdução}

As pesquisas na área de Lingüística Aplicada têm mostrado que o professor tem dificuldades em avaliar qual a concepção de ensinoaprendizagem de língua e mesmo a concepção de gramática que deve nortear seu trabalho. De acordo com Batista (1997), infelizmente os saberes associados à tradição gramatical possuem características que os tornam adequados a uma transmissão disciplinada que favorece a consecução da finalidade corretiva da interlocução, assim como o reforço da autoridade do professor, permitindo-lhe manter o domínio da interlocução. Segundo o mesmo autor, trata-se de conhecimentos parceláveis e passíveis de serem organizados em séries progressivas. Trata-se ainda de um conjunto de saberes sobre a língua que formam um sistema de conteúdos abstratos; e finalmente, completa Batista (1997), trata-se de um conjunto de saberes e de regras que definem uma visão normativa da língua, designando o certo e o errado no que diz respeito ao seu uso.

Acreditamos que a mudança que o professor de língua materna precisa fazer em sua prática pedagógica, certamente, vai além de uma simples "modernização" da nomenclatura; o que precisa ser modificado é o ponto de vista sobre a língua/linguagem, sobre seu funcionamento nos discursos; é o olhar sobre os textos; é a compreensão de que refletir sobre as práticas de linguagem ultrapassa a mera explicitação de uma terminologia voltada quase que exclusivamente para aspectos morfossintáticos ao nível de frase. Defendemos que desenvolver práticas de linguagem em si implica também uma atividade reflexiva sobre as práticas orais e escritas. Isto quer dizer que o trabalho com a linguagem implica uma reflexão metalingüística.

Vê-se, portanto, que para além da manipulação da terminologia gramatical tradicional, a reflexão sobre o funcionamento dos textos e dos discursos abre um vasto campo que precisa ser explorado em sala de aula. 
Essa reflexão metalingüística, com certeza, concorre para o enriquecimento da compreensão e produção oral e escrita dos alunos. É necessário ressaltar que as atividades metalingüísticas não constituem um fim em si, mas são um meio para facilitar o enriquecimento da competência comunicativa dos alunos, de seu savoir-faire discursivo.

Observando nosso quadro educacional, verificamos que um outro aspecto muito importante precisa ser considerado: a diversidade lingüística. Bortoni-Ricardo insiste que

[...] a função da escola, no processo de aquisição da linguagem, não é ensinar o vernáculo, pois este os alunos já trazem consigo ao iniciar sua escolarização, pois o adquirem na sua rede primária de relações da família e vizinhos. A função da escola é justamente desenvolver outras variedades que se vão acrescer ao vernáculo básico. (BORTONI-RICARDO, 2002, p. 345)

Assim como Bortoni-Ricardo (2004) e Bagno (2003), inseridos no quadro da sociolingüística educacional, concordamos que o professor precisa saber intervir, de acordo com as pesquisas lingüísticas mais recentes, diante das variedades estigmatizadas da língua. Infelizmente, nota-se ainda que o tratamento dado, em especial, às atividades de produção textual, não considera as questões levantadas anteriormente. Muitas vezes a atividade de produção textual ocorre a partir da indicação do professor de um tema ou de um "tema livre" com algumas orientações que ele considera importantes, ressaltando, principalmente, a importância da "correção" da linguagem.

Dessa forma, temos a convicção de que, no processo de intervenção didática em língua materna, é importante considerar os vários elementos que influenciam a intervenção. Pensar a intervenção didática em língua materna implica refletir sobre os elementos de base que a influenciam: as concepções que o professor possui de língua/linguagem, de ensino/aprendizagem e de avaliação; suas representações do contexto socioinstitucional, das práticas sociais de linguagem e das diretrizes oficiais do ensino; e também as condições socioinstitucionais nas quais o professor opera. Percebe-se que a 
avaliação torna-se um elemento central que perpassa os demais. A partir do momento que todos esses elementos são considerados como integrados ao processo pedagógico, a importância da complexidade dessa questão é definida.

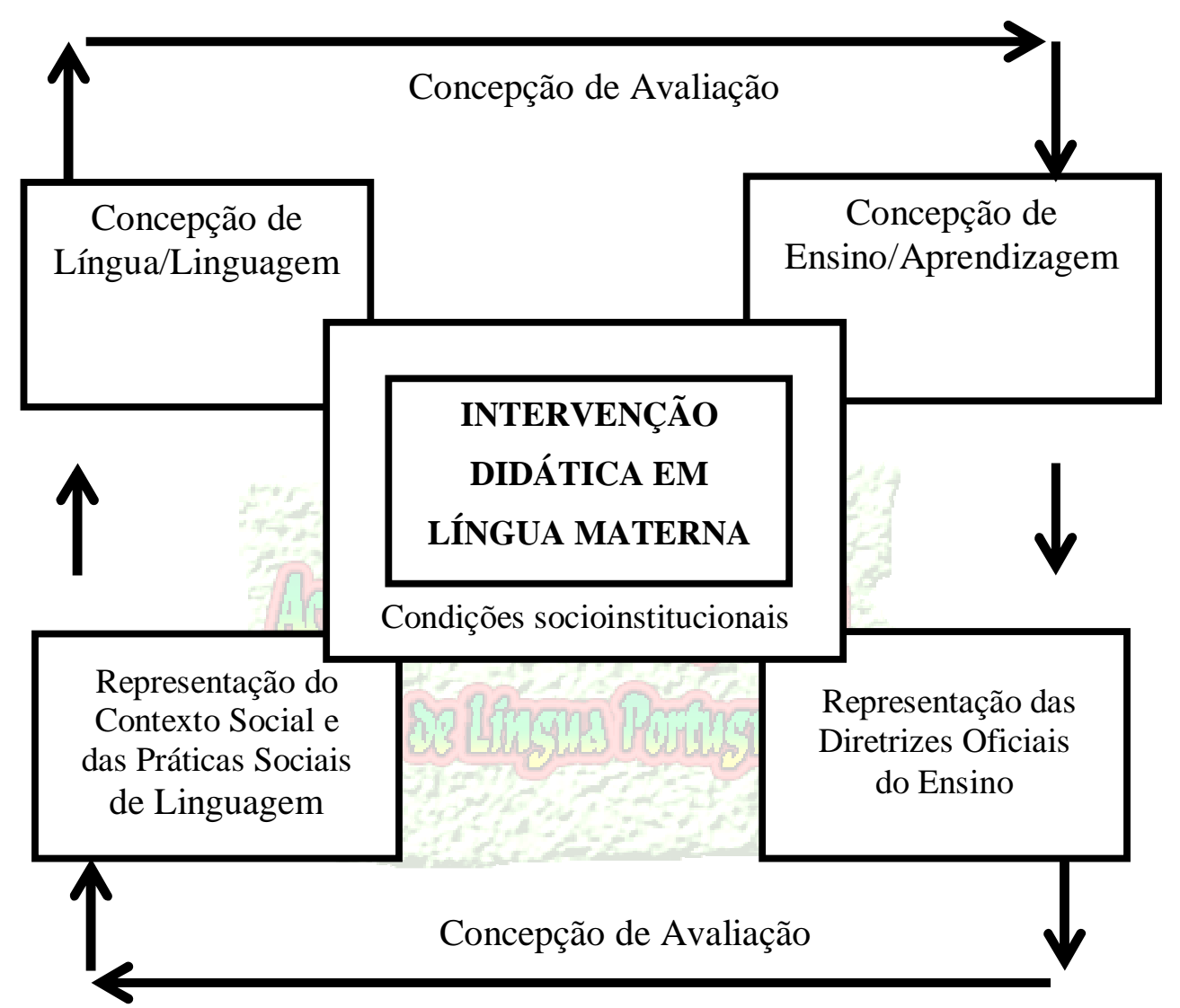

Figura 1 - Elementos que influenciam a intervenção didática (Adaptado de PEREIRA, 2001).

\section{A avaliação formativa e o processo da produção textual em uma abordagem interacional}

Consideramos que a prática da avaliação formativa pode ser uma das modificações nos modos de intervenção didática a partir do momento em que se adota uma abordagem interacional de ensino-aprendizagem da língua materna (Cf. PEREIRA, 2001). Petitjean (1984, p. 10) afirma que 
“[...] a avaliação formativa é interna ao processo de aprendizagem, é contínua, é mais analítica e centrada no aprendiz do que no produto final."

$\mathrm{O}$ aprendiz, tendo um papel ativo na aprendizagem, passa a ter uma maior autonomia. Isso implica que se desenvolvam capacidades autoavaliativas conscientes. $\mathrm{O}$ aprendiz precisa se apropriar dos critérios de avaliação. A auto-avaliação, enquanto parte integrante do processo de ensino-aprendizagem, torna-se uma estratégia didática.

É interessante aproximar auto-avaliação e co-avaliação, pois, geralmente, trabalham-se as duas juntas. É normalmente mais fácil ser leitor do outro que ser o próprio leitor. Existe um distanciamento natural em relação ao texto do outro, enquanto que com o próprio texto há o produto de uma reflexão e mais a própria reflexão, o que impede de se ver, muitas vezes, o que realmente foi produzido. Normalmente, o outro analisa o texto com uma visão crítica, não com a idéia de desmerecer o trabalho de seu colega, mas com o intuito de melhorá-lo. Nesse sentido, é possível o autor ser cada vez mais capaz de olhar com distanciamento o próprio texto. A partir do momento que o professor de língua materna favorece atividades de cunho metacognitivo, ele estará favorecendo a prática da avaliação formativa.

Séguy (1994) enfatiza a importância de o aprendiz mobilizar critérios para avaliar o seu texto, como também o texto do colega. Dessa forma, ele mostra que o aluno passará a considerar a escrita e a reescrita como atividades fundamentais. David (1991) também observa que é primordial que as crianças saibam retornar ao seu texto utilizando o conjunto de procedimentos à sua disposição; elas precisam se desfazer da idéia de que um texto está acabado desde o primeiro esboço.

O objetivo, portanto, é que o aprendiz saiba se auto-avaliar para que seja capaz de melhorar sua performance. Neste sentido, é indispensável que seja implementada uma outra gestão dos erros, a fim de que eles não sejam mais considerados como fracassos para estigmatizar, mas como traços de 
um verdadeiro trabalho e como os lugares a partir dos quais seja possível compreender melhor as dificuldades e ajudar a superá-las, tendo em vista as especificidades dos diversos gêneros textuais nas práticas sociais de linguagem. Daí considerarmos a importância do trabalho de escriturarevisão-reescritura ${ }^{1}$ como um processo interdependente. Do ponto de vista da prática didática sobre o texto,

[...] a reescritura vai ocupar um duplo lugar: o de objetivo (se escrever é reescrever, então aprender a escrever é aprender a reescrever) e o de meio (reescrever pode ajudar a aprender a escrever através de vários dispositivos e procedimentos). (REUTER, 1996, p. 170).

\section{A escritura-revisão-reescritura no ensino-aprendizagem da língua materna}

A definição e o papel central dos critérios de avaliação e reescritura têm constituído um dos desenvolvimentos essenciais da pesquisa do grupo Évaluation $(\mathrm{EVA})^{2}$.

"Esses critérios são objeto de escolhas que têm por função hierarquizar as características do texto a ser produzido. Conforme os procedimentos provenientes da avaliação formativa, seu papel é duplo. Por um lado, no desenvolvimento de cada projeto de escritura, eles permitem agir eficazmente na construção e regulação progressiva do texto. Por outro, a elaboração dos critérios constitui um meio fundamental de construção de saberes." (SÉGUY, 1994, p. 26).

A equipe EVA propôs um quadro teórico - Classificação dos lugares de intervenção didática (CLID) — que definiu classes de critérios e determinou lugares de intervenção didática, levando em conta as unidades textuais tratadas e os pontos de vista adotados para sua avaliação (pragmático, semântico, morfossintático e material) [ver Anexo 1].

Segundo Turco et al.,

\footnotetext{
${ }^{1}$ Ao longo do texto, serão também utilizados os termos "escritura" e "reescritura" entendendo-os como aquilo que está sendo desenvolvido pelo aluno, o processo de produção textual, o trabalho de escrita e reescrita. E o "escrito" e o "reescrito" como a produção do aluno; seu texto.

${ }^{2} \mathrm{O}$ grupo Évaluation (EVA) - Avaliação - pertence ao Institut National de Recherches Pédagogiques (INRP), grupo de pesquisa da França. Esta equipe trabalha com as práticas de avaliação dos textos dos alunos em sala de aula.
} 
[...] o quadro de avaliação formativa postula a utilização de critérios como elementos determinantes, ao mesmo tempo na atividade de escritura e na atividade de reescritura... O CLID permite elaborar ferramentas para analisar as modificações trazidas nos textos pelos alunos e a pertinência das reescrituras realizadas. [...] Os mesmos critérios são então utilizados para escrever, para avaliar e para reescrever. [...] Assim, a apresentação tabular coloca sobre o mesmo plano os elementos que o compõem; ela não privilegia nenhum dos retângulos do quadro [...] (TURCO et al., 1994, p. 68).

A elaboração, com os alunos, de critérios de avaliação dos textos é uma estratégia didática a ser implementada pelo professor de língua materna. Tivemos a oportunidade de constatar em pesquisa realizada em 2000 (PEREIRA, 2001), a implementação de códigos para revisão de texto (ver Anexo 2) como uma importante estratégia didática no processo de escritura-revisão-reescritura dos diversos gêneros textuais.

Portanto, as atividades de escritura-revisão-reescritura serão importantes desde que sejam vistas como atividades que envolvam a interação em todos os níveis: o texto como forma de interação; o professor que promove a interação do aluno com seu texto; $\mathrm{o}$ aluno que reconhece sua interação constante com o texto a produzir; a interação do aluno com seus pares na escritura e reescritura do texto; a interação do leitor com o alunoautor... Enfim, a interação permeando toda a atividade de escritura e reescritura. Vista desta forma, não se pode conceber a atividade de linguagem escrita como uma atividade solitária, de produção exclusivamente individual. A aprendizagem acontece na interação que o professor, como elemento mais importante da intervenção didática, é capaz de promover em todos os níveis já citados, para desenvolver uma real competência escritural no aluno.

Sobre o aspecto da reescritura, Turco et al. (1994) falam da necessidade de construir situações de ensino da revisão que levarão à sistematização da reescritura através dos processos de apagamento, acréscimo, substituição e deslocamento. Essas atividades de formulação e 
reformulação confirmam que as atividades metalingüísticas estão presentes na interação didática, propiciando constantemente a reflexão sobre a língua, os textos e os discursos a partir de uma concepção interacional da língua. $\mathrm{O}$ modelo que é proposto faz aparecer claramente o caráter prioritário da avaliação e, como mostraram os trabalhos do grupo EVA, o objetivo central dos critérios de avaliação.

A equipe Révision $(\mathrm{REV})^{3}$ tentou elaborar um modelo das competências implementadas pelos alunos quando eles revisam seus textos (ver Anexo 3). As competências de revisão são definidas como um conjunto de saberes, de saber-fazer e de representações concernentes ao texto. De acordo com Turco et al.

[...] o modelo é construído em torno do núcleo central constituído por diferentes saber-fazer: o saber-revisar em si é constituído de duas operações realizadas em relação com a capacidade do escritor em analisar a tarefa de escritura (7) reler o texto (8) em curso de escritura e/ou ao fim da produção, para identificar os eventuais pontos de disfunção, definir sua natureza e reescrever (9) tudo ou parte das passagens concernidas. (TURCO et al., 1994, p. 75)

O saber-revisar aparece estreitamente ligado à capacidade de mobilizar os saberes relativos aos textos e à escritura: saberes sobre os textos (4) que remetem, em particular, às tipologias ${ }^{4}$ e aos tratamentos didáticos; saberes sobre o funcionamento dos textos (5); saberes sobre o mundo dos escritos e sobre os escritos (10) que fazem parte das experiências (familiar, social, escolar) acumuladas no passado por cada aluno; saberes sobre as operações de escritura (11) e as propriedades esperadas do texto (12), que remetem ao modelo de análise do saberescrever dos alunos; saberes sobre os recursos da língua (6).

Como escreveu Dabène apud Turco et al. (1994, p. 76), a propósito da competência escritural, “[...] saber-fazer e saberes são também

\footnotetext{
${ }^{3}$ A pesquisa do INRP-REV tem por objetivos identificar os saberes e o saber-fazer "ensináveis" em matéria de revisão e de reescritura; determinar as condições didáticas e pedagógicas de seu ensino-aprendizagem e produzir ferramentas para sala de aula permitindo aos próprios professores construírem os módulos de aprendizagem.

${ }^{4}$ Atualmente, a terminologia gêneros textuais é a mais adotada nesse sentido.
} 
determinados por representações que agem sobre os modos de pensamento, de ação dos alunos e dos professores." Segundo Turco et al. (1994), cada um dos seis retângulos laterais do modelo apresenta um ponto a respeito do qual as representações aparecem como dominantes para a produção e a revisão dos textos; duas representações contrastadas são apresentadas e concernem a um referente teórico ou a um ponto de referência relacionado ao ensino-aprendizagem da produção de texto na escola: no alto, uma representação tradicional, que corresponde a uma prática dominante; embaixo, uma representação mais atual, esclarecida por contribuições científicas.

A seta que as religa não significa que se deve abandonar uma representação pela outra, mas que é sem dúvida útil fazer evoluir a primeira integrando pontos de vista da segunda, de modo a constituir uma representação mais completa, mais aberta. (TURCO et al., 1994, p. 76).

A implementação de situações de ensino da escritura-revisãoreescritura passam por um conhecimento exato das práticas e das representações dos professores.

Nesse sentido, a sociolingüística educacional também tem dado importantes contribuições para o processo de escritura-revisão-reescritura no ensino-aprendizagem da língua materna (cf. BORTONI-RICARDO, 2004, 2005, 2006a, 2006b). Bortoni-Ricardo (2005, p. 130-133) enfatiza que é preciso contribuir para o desenvolvimento de uma pedagogia que seja sensível às diferenças sociolingüísticas e culturais dos alunos e aponta seis princípios fundamentais na implementação da sociolingüística educacional:

1- A influência da escola na aquisição da língua não deve ser procurada no dialeto vernáculo dos falantes, mas em seus estilos formais, monitorados.

2- O segundo princípio refere-se ao caráter simbólico das regras variáveis. Regras que não estão associadas à avaliação negativa na 
sociedade, não são objeto de correção na escola e, portanto, não vão influir consistentemente nos estilos monitorados.

3- Este princípio relaciona-se à inserção da variação sociolingüística na matriz social. No Brasil, a variação está ligada à estratificação social e à dicotomia rural-urbano. Estudos revelam que professores sensíveis às diferenças sociolingüísticas e culturais desenvolvem intuitivamente estratégias interacionais em sala de aula bastante positivas. O aluno é ratificado pelo professor e pelos colegas como um falante legítimo e começa a alternar seu dialeto vernáculo e a língua de prestígio, principalmente quando está realizando eventos de letramento.

4- Os estilos monitorados de língua são reservados à realização de eventos de letramento em sala de aula. Para a realização de eventos de oralidade, podemos nos valer de estilos mais casuais.

5- A descrição da variação na sociolingüística educacional não pode ser dissociada da análise etnográfica e interpretativa da variação na sala de aula. O ponto de partida da sociolinguíistica educacional é a análise minuciosa do processo interacional, na qual se avalia o significado que a variação assume.

6- O sexto princípio refere-se ao processo de conscientização crítica dos professores e alunos quanto à variação e à desigualdade social que ela reflete. Nesse processo, é preciso que se estabeleça um efetivo diálogo com o professor por meio de pesquisa que o enriqueça e o torne apto a promover uma auto-reflexão e uma análise crítica de suas ações (pesquisa de empoderamento e pesquisa colaborativa).

Bortoni-Ricardo ressalta que, especialmente, o professor alfabetizador precisa

[...] fazer a distinção entre problemas na escrita e na leitura que decorrem da interferência de regras fonológicas variáveis e outros que se explicam simplesmente pela falta de 
familiaridade do alfabetizando com as convenções da língua escrita. (BORTONI-RICARDO, 2006b, p268)

E apresenta um importante diagrama:

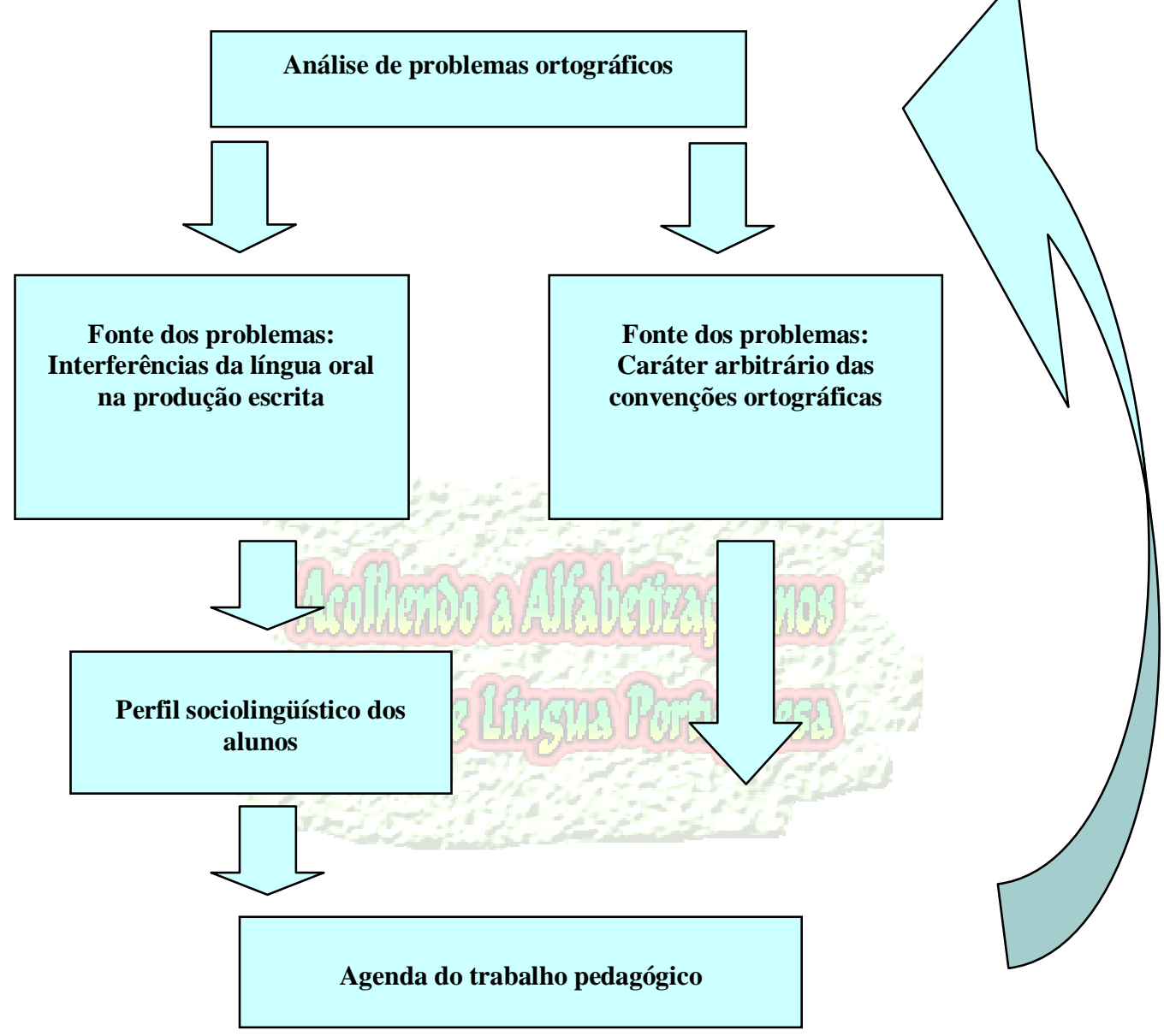

Figura 2 - Análise de problemas ortográficos (BORTONI-RICARDO, 2006b, p.268).

Diante disso é importante organizar seqüências didáticas que reduzam parte da complexidade da tarefa no que se refere aos processos de escritura-revisão-reescritura. Um dos aspectos para que uma aprendizagem bem sucedida ocorra é que o professor delimite com e para os aprendizes os reais objetivos $\mathrm{da}(\mathrm{s})$ atividade(s) a desenvolver. Normalmente, estes objetivos não são delimitados, mas o professor exige o domínio do conjunto 
das capacidades necessárias para a escritura e a reescritura dos diversos gêneros textuais. Sabe-se que ao produzir um texto, o autor precisa coordenar uma série de aspectos: o que dizer, a quem dizer, como dizer, visando um objetivo. Espera-se que o aprendiz coordene sozinho todos eles. Não há como considerar para o aluno o caráter dialógico do texto dissociado de uma prática pedagógica condizente com os objetivos da língua materna.

\section{Considerações finais}

Acreditamos que a avaliação formativa é uma modificação importante nos modos de intervenção quando se concebe uma abordagem interacional no processo de ensino-aprendizagem da língua materna. Uma regulação eficiente implica a participação efetiva do aprendiz na construção de conhecimentos declarativos e procedimentais, propiciando-se, assim, o desenvolvimento de competências. A avaliação formativa não é somente desenvolver capacidades nos alunos, obtendo, no final, o produto esperado socialmente. É também poder verificar a existência de competências efetivas que são visadas pela instituição e, principalmente, formar um indivíduo que tenha capacidade de se expressar e manejar as diferentes variedades da língua nas diversas situações de interação. Assim, ao mesmo tempo, há o favorecimento do processo ensino-aprendizagem e a resposta a uma expectativa socioinstitucional. A concepção atual de avaliação formativa prioriza as atividades de auto-regulação da ação e, portanto, da reflexão sobre a ação e sobre as estratégias envolvidas. Neste sentido, está diretamente relacionada com uma abordagem interacional no processo de ensino-aprendizagem da língua materna.

\section{Referências bibliográficas}

BAGNO, Marcos (2003). A norma oculta: língua \& poder na sociedade brasileira. São Paulo: Parábola. 
BATISTA, Antonio Augusto Gomes (1997). Aula de Português: discurso e saberes escolares. São Paulo: Martins Fontes.

BORTONI-RICARDO, Stella Maris (2002). Um modelo para a análise sociolingüística do português do Brasil. In: BAGNO, Marcos (Org.). Lingüística da norma. São Paulo: Loyola, p. 333-350.

(2004). Educação em Língua Materna: a sociolingüística na sala de aula. São Paulo: Parábola.

(2005). Nós cheguemu na escola, e agora?: sociolingüística e educação. São Paulo: Parábola Editorial.

(2006a). Trabalhando regras variáveis morfossintáticas nas séries iniciais. In: SILVA, C. R.; HORA, D.; CHRISTIANO, M. E. A. (Orgs.). Linguiística e Práticas Pedagógicas. Santa Maria: Palotti. p. 11-31.

(2006b). O estatuto do erro na língua oral e na língua escrita. In: GORSKI, E. M.; COELHO, I. L. (Orgs.). Sociolinguiística e ensino: contribuições para formação do professor de língua. Florianópolis: UFSC, p.267-276.

DAVID, Jacques (1991). Écrire, une activité complexe étayée par la parole: étude des échanges oraux dans des tâches de réécriture menées par des enfants de 7 ans. Repères, Paris, INRP, n. 3, p. 25-44.

GROUPE EVA (1991), Évaluer les écrits à l'école primaire. Paris: Hachette/INRP. (Coll. "Pédagogies pour demain/Didactiques").

PEREIRA, Ana Dilma de Almeida. A problemática da intervenção em uma abordagem interacional de ensino-aprendizagem da língua materna. 2001. 2 v. 212 f. Dissertação (Mestrado em Lingüística) - Centro de Letras e Artes, Universidade Federal do Pará, Belém.

PETITJEAN, Brigitte (1984). Formes et fonctions des différents types d'évaluation. Pratiques, Metz, CRESEF, n. 44, p. 5-20.

REUTER, Yves (1996). Enseigner et apprendre à écrire: construire une didactique de l'écriture. Paris: ESF. (Coll. Pédagogies).

SÉGUY, André (1994). Écrire et réécrire en classe, pour quoi faire?: finalisation des écrits et critères de réécriture. Repères, Paris, INRP, n. 10, p. 13-31. 
TURCO, Gilbert; PLANE, Sylvie; MAS, Maurice (1994). Costruire des compétences em révision/réécriture au cycle 3 de l'école primaire. Repères, Paris, INRP, n. 10, p. 67-81.

\section{Autora}

\section{Ana Dilma de Almeida Pereira}

Universidade de Brasília

anadilma.almeida@globo.com

\section{Como citar este artigo:}

PEREIRA, Ana Dilma de Almeida. O tratamento do "erro" nas produções textuais: a revisão e a reescritura como parte do processo de avaliação formativa. Revista ACOALFAplp: Acolhendo a Alfabetização nos Países de Língua portuguesa, São Paulo, ano 2, n. 3, 2007. Disponível em: <http://www.mocambras.org> e ou <http://www.acoalfaplp.org>. Publicado em: setembro 2007. 


\section{Anexo 1}

\section{QUESTÕES PARA AVALIAR AS PRODUÇ̃̃ES TEXTUAIS}

\begin{tabular}{|c|c|c|c|}
\hline \begin{tabular}{|l} 
Ponto \\
\\
\end{tabular} & TEXTO NO SEU CONJUNTO & RELAÇÕES ENTRE AS FRASES & FRASES \\
\hline PRAGMÁTICO & $\begin{array}{l}1 \text { - O autor leva em conta a situação (quem fala? a } \\
\text { quem? para fazer o quê?)? } \\
\text { - Escolheu um tipo de escrita adaptado (carta, ficha } \\
\text { técnica, conto...)? } \\
\text { - O escrito produz o efeito almejado (informar, } \\
\text { divertir, convencer...)? }\end{array}$ & $\begin{array}{l}4 \text { - A função de orientação do leitor é assegurada? } \\
\text { (utilização de organizadores textuais: por um lado... por } \\
\text { outro; em primeiro lugar, em seguida, enfim...) } \\
\text { - A coerência temática é satisfatória? (progressão } \\
\text { da informação, ausência de ambigüidades nos } \\
\text { encadeamentos...) }\end{array}$ & $\begin{array}{l}7 \text { - A construção das frases é variada, adaptada } \\
\text { ao tipo de escrito? (diversidade na escolha das } \\
\text { informaçõos colocadas em início de frase...) } \\
\text { - As marcas da enunciaçãao são interpretáveis, } \\
\text { adaptadas (sistema da narração ou do discurso, } \\
\text { utilização de demonstrativos...) }\end{array}$ \\
\hline SEMÂNTICO & $\begin{array}{l}2 \text { - A informação é relevante e coerente? } \\
\text { - A escolha do tipo de texto é apropriada? (narrativo, } \\
\text { explicativo, descritivo...) } \\
\text { - O vocabulário, no seu conjunto, e o registro de } \\
\text { língua são homogêneos e adequados ao tipo de escrito } \\
\text { produzido? }\end{array}$ & $\begin{array}{l}\text { 5 - A coerência semântica é assegurada? (ausência de } \\
\text { contradição de uma frase para a outra, substitutos } \\
\text { nominais apropriados, explícitos...) } \\
\text { A articulação entre as frases ou orações é } \\
\text { eficientemente marcada (escolha dos conectores: mas, } \\
\text { se, portanto, todavia...)? }\end{array}$ & $\begin{array}{l}8 \text { - O léxico é adequado? (ausência de imprecisões ou } \\
\text { confusões no uso das palavras) } \\
- \text { As frases são aceitáveis do ponto de vista } \\
\text { semântico? (ausência de contradições, de } \\
\text { incoerências...) }\end{array}$ \\
\hline MORFOSSINTÁTICO & $\begin{array}{l}3 \text { - O modo de organização corresponde ao(s) tipo(s) de } \\
\text { texto(s) escolhido(s)? } \\
\text { - Levando-se em conta o tipo de texto, o sistema } \\
\text { dos tempos é pertinente? Homogêneo? (por ex.: pretérito } \\
\text { imperfeito / perfeito para uma narração...) } \\
\text { - Os valores dos tempos verbais são dominados? }\end{array}$ & $\begin{array}{l}6 \text { - A coesão sintática é realizada? (utilização dos } \\
\text { artigos definidos, pronomes...) } \\
\text { - A coesão temporal é realizada? } \\
\text { A concordância dos tempos e dos modos é } \\
\text { respeitada? }\end{array}$ & $\begin{array}{l}9 \text { - A sintaxe da frase é gramaticalmente aceitável? } \\
\text { - A morfologia verbal é dominada? (ausência } \\
\text { de erros de conjugação) } \\
\text { - A ortografia segue as normas? }\end{array}$ \\
\hline $\begin{array}{c}\text { ASPECTOS } \\
\text { MATERIAIS }\end{array}$ & $\begin{array}{l}\text { 10 - O suporte foi bem escolhido? (caderno, ficha, } \\
\text { painel, mural...) } \\
\text { - A tipografia é adequada? (estilo e tamanho dos } \\
\text { caracteres) } \\
\text { - A organização da página é satisfatória? } \\
\text { (eventual presença de esquemas, ilustrações...) }\end{array}$ & $\begin{array}{l}11 \text { - A segmentação das unidades do discurso é } \\
\text { pertinente? (organização em parágrafos, disposição } \\
\text { tipográfica com recuo, subtítulos...) } \\
\text { - A pontuação delimitando as unidades do discurso } \\
\text { é dominada? (pontos, pontuação do diálogo...) }\end{array}$ & $\begin{array}{l}12 \text { - A pontuação da frase é dominada? (vírgulas, } \\
\text { parênteses...) } \\
\quad \text { - As maiúsculas são empregadas conforme as } \\
\text { regras? (início de frase, nos nomes próprios...) }\end{array}$ \\
\hline
\end{tabular}

Classificação dos lugares de intervenção didática (Groupe Eva, 1991, p. 57). 


\section{Anexo 2}

\section{SUGESTÃO DE CÓDIGOS DE REVISÃO DE TEXTO}

textos.

É importante que o aluno procure sempre e cada vez mais aperfeiçoar a sua capacidade de observar para que ele mesmo possa fazer a REVISÃO de seus

Especialmente nas produções escritas dos alunos, freqüentemente se observam "desvios" de ortografia, acentuação, pontuação, concordância, ordenação das idéias, etc.

Observando o código de revisão de textos, o aluno terá condições de operar a REESCRITA de seu texto.

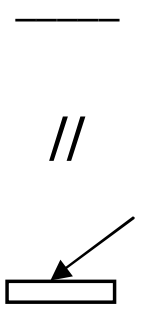

Traço embaixo da palavra indica problema na ortografia.

As barras indicam problema na pontuação.

O retângulo e a seta, cercando expressões ou frases, indicam problemas na concordância.

$\mathrm{O}$ asterisco indica falta de sentido e clareza nas idéias expostas.

与 $\mathrm{O}$ traço sinuoso na vertical indica que é preciso fazer parágrafo.

O traço sinuoso na horizontal indica que faltou escrever até o limite da margem.

Dois traços embaixo da palavra e a seta indicam problemas na separação silábica das palavras.

É preciso orientar o aluno de que ele é o autor do seu texto. Ele pode e deve modificá-lo, acrescentando novas idéias e retirando outras. Ele pode tornar o texto mais interessante e criativo no momento da REESCRITA.

O código de revisão de textos, na verdade, é uma pista para que o aluno possa fazer a sua REESCRITA, indo buscar, procurar, pesquisar o que é mais adequado para seu texto a fim de que qualquer pessoa que o leia, compreenda o que ele quis dizer. 
Outros códigos podem ser criados a partir da complexidade dos diversos gêneros textuais que forem sendo trabalhados.

\section{Anexo 3}

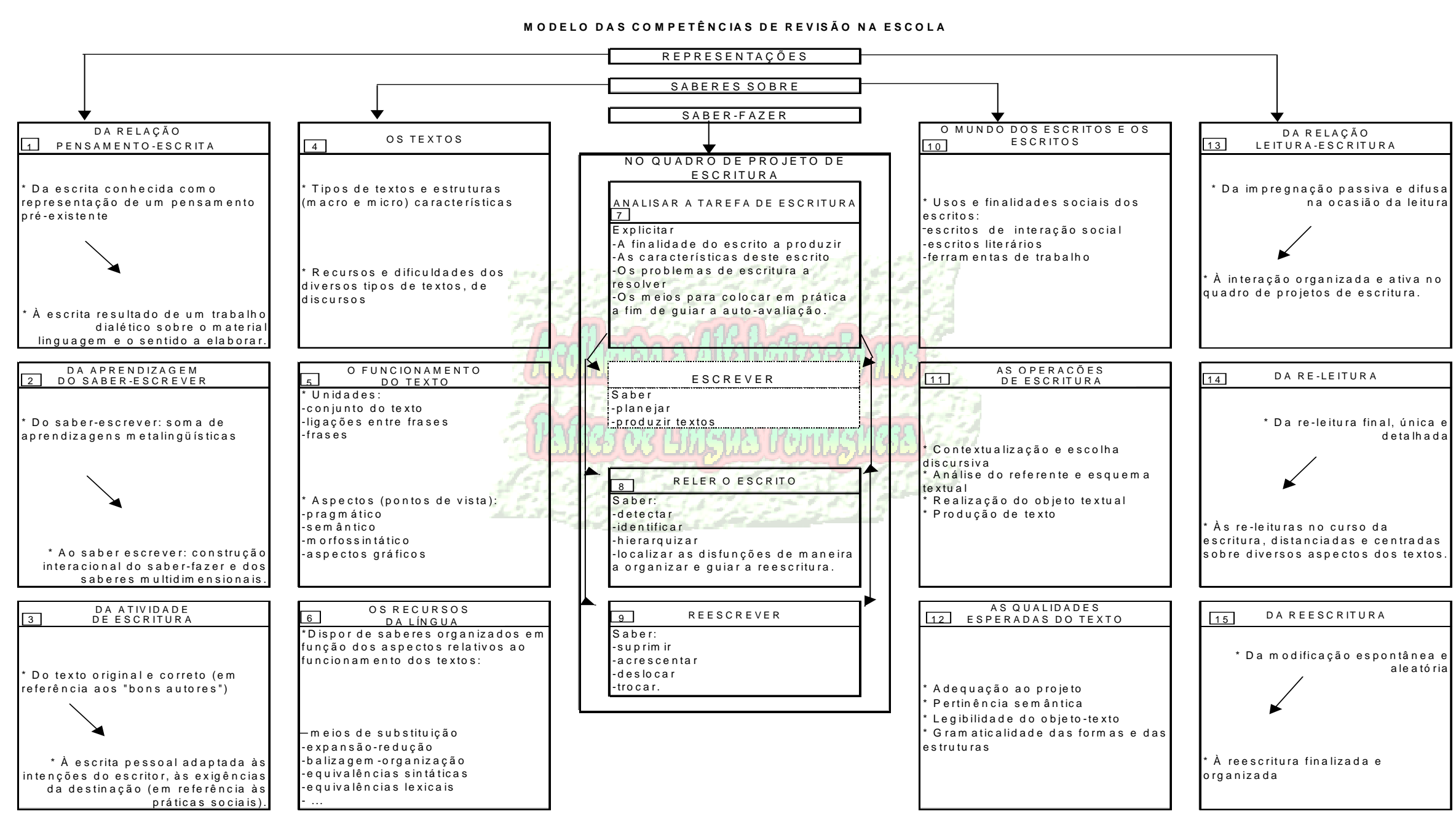

TURCO, Gilbert; PLANE, Sylvie; MAS, Maurice. Construire des compétences en révision/réécriture au cycle 3 de l'école primaire. Repères, Paris: INRP, n.10, p.67-81, 1994.

Ou
PEREIRA, Ana Dilma de Almeida. A problemática da intervenção em uma abordagem interacional de ensino-aprendizagem da língua materna. Belém, 2001. 2v. 212 f. Dissertação (Mestrado em Lingüística).
Centro de Letras e Artes. Universidade Federaldo Pará. 67

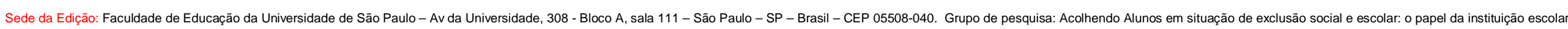
Parceria: Centro de Recursos em Educação Não-Formal de Jovens e Adultos - CRENF - FacEd - UEM - Prédio da Faculdade de Letras e Ciências Sociais - Segundo Piso - Gabinete 303 - Campus Universitário Maputo, Moçambique, África

Setembro de 2007/ Fevereiro de 2008 - Ano II - №. 003 